\title{
A phase II study evaluating the toxicity and efficacy of single-agent temsirolimus in chemotherapy-naïve castration-resistant prostate cancer
}

\author{
K Kruczek $^{1,5}$, M Ratterman ${ }^{1}$, K Tolzien ${ }^{2}$, S Sulo ${ }^{3}$, T M Lestingi ${ }^{2}$ and C Nabhan ${ }^{\star} 4$ \\ ${ }^{1}$ Department of Medicine, Advocate Lutheran General Hospital, Park Ridge, IL, USA; ${ }^{2}$ Oncology Specialists, SC, Park Ridge, IL, \\ USA; ${ }^{3}$ Russell Institute for Research and innovation, Advocate Lutheran General Hospital, Park Ridge, IL, USA and ${ }^{4}$ Department of \\ Medicine, Section of Hematology and Oncology, The University of Chicago, Chicago, IL, USA
}

Background: The mammalian target of rapamycin (mTOR) pathway is deregulated in castration-resistant prostate cancer (CRPC). We investigated the efficacy and toxicity of temsirolimus, an mTOR inhibitor, in chemotherapy-naïve CRPC.

Methods: In this phase II open label study, eligible patients received IV temsirolimus at $25 \mathrm{mg}$ weekly until objective disease progression, unacceptable toxicity or investigator's discretion. Toxicity was assessed every 4 weeks and responses every 8 weeks. Primary end point was calculating the overall response (OR) rate as well as measuring stable disease (SD) to assess the overall clinical benefit calculated as OR+SD. Secondary end points included prostatic-specific antigen (PSA) changes and time to progression biochemically and radiographically. Correlative studies included prospective assessment of quality of life ( $\mathrm{Q} o L)$ using two previously validated scales.

Results: Although the sponsor halted the study early, 21 patients were enrolled of which, 15 were evaluable for efficacy and OR. Median age was 74 (range: 57-89), median PSA was $237.5 \mathrm{ng} \mathrm{ml}^{-1}$ (range: 8.2-2360), visceral disease present in 11 patients (52\%), and 17 patients (81\%) patients had Gleason score (7-10). Two patients had a partial response (PR) and eight had SD. The OR was $13 \%(2 / 15)$ and the overall clinical benefit (OR + SD) was 67\% (10/15). Median time to radiographic disease progression was 2 months (range 2-10 months). Biochemical response assessment was available for 14/15 patients. Any PSA decline was observed in four patients $(28.5 \%$; $4 / 14)$ with one patient $(7 \%)$ having $>50 \%$ PSA decline. Median time to progression by PSA was 2 months (range 1-10 months). With a median follow-up of 32 months, median overall survival (OS) was 13 months (range: 2-37) and three patients remain alive at the data cutoff (5/2013) for an OS of $14 \%$ at 4 years on an intent-to-treat analysis. Major non-haematologic toxicities included fatigue (19\%) and pneumonia (14\%). Main laboratory toxicities included hyperglycaemia (24\%) and hypophosphatemia (14\%). Also, 52\% of enrolled patients had serious adverse events. Other toxicities were consistent with previously reported adverse events with temsirolimus. Despite these observed adverse events, temsirolimus did not adversely impact QoL.

Conclusion: Temsirolimus monotherapy has minimal activity in chemotherapy-naïve CRPC.

\footnotetext{
*Correspondence: Associate Professor C Nabhan; E-mail: cnabhan@medicine.bsd.uchicago.edu

Presented in part as an abstract at the American Society of Clinical Oncology/Genitourinary Symposium, San Francisco, CA, February 2012.

${ }^{5}$ Currently at The Division of Hematology and Oncology at Loyola University Medical Center, Maywood, IL.
}

Received 27 June 2013; revised 2 August 2013; accepted 9 August 2013; published online 5 September 2013

(c) 2013 Cancer Research UK. All rights reserved 0007-0920/13 
With close to 30000 deaths annually, prostate cancer remains the second most common cause of cancer-related deaths in US men (Siegel et al, 2013). Further, this disease carries substantial morbidity and mortality in European countries. (Shibata and Whittemore, 2001; Neppl-Huber et al, 2012) Although therapeutic choices for castration-resistant prostate cancer (CRPC) have expanded recently beyond docetaxel-based chemotherapy, median survival remains suboptimal at less than 2 years. (de Bono et al, 2010; Kantoff et al, 2010; de Bono et al, 2011; Scher et al, 2012).

Multiple mechanisms for the emergence of CRPC have been proposed and continue to be investigated.(Debes and Tindall, 2004) These have been generally divided into pathways dependent on the androgen receptor (AR) and others that are activated independent of the AR (Chen et al, 2004). Understanding the molecular aspects of CRPC evolution has allowed for the development of targeted agents specifically designed to inhibit pathways implicated in the proliferation and growth of malignant cells (Nabhan et al, 2011). The phosphatase and tensin homologue (PTEN) tumour suppressor gene is commonly mutated in CRPC eliminating the inhibitory effect on the phosphatidylinositol 3-kinase (PI3K) pathway causing overproduction of AKT and subsequent cell proliferation and survival (Li et al, 1997; Debes and Tindall, 2004). Whether PTEN mutations contribute to the evolution or to the development of CRPC remains debated (Pourmand et al, 2007). Notably, This PI3K/AKT/mammalian target of rapamycin (mTOR) pathway has been linked to both tumourogenesis and resistance to therapy in prostate cancer and in other solid tumours as it is often deregulated during disease progression (Burgio et al, 2012).

Temsirolimus is an mTOR inhibitor that is currently approved for treatment of patients with metastatic renal cell carcinoma including the subset with adverse prognostic features (Gore, 2007). Given the importance of this mTOR pathway in CRPC evolution and the witnessed activity of temsirolimus in renal cancer, we sought to investigate whether temsirolimus has activity in patients with CRPC that are chemotherapy-naïve. Herein, we report the final results of this phase II, open label, single-institution study.

\section{PATIENTS AND METHODS}

Patients. Eligible patients were $\geqslant 18$ years of age, with a diagnosis of CRPC per standard definition.(Scher et al, 2008) Patients had an Eastern Cooperative Oncology Group (ECOG) performance status of $\leqslant 2$ with measurable disease biochemically (using serum prostatic-specific antigen (PSA) measurements, with PSA of at least $5 \mathrm{ng} \mathrm{ml}^{-1}$ at baseline) and/or radiographically (using bone scans and/or computed tomography of measurable disease areas). Patients were required to have adequate bone marrow function (absolute neutrophil count $\geqslant 1000 \mu \mathrm{l}^{-1}$, haemoglobin $\geqslant 9.0 \mathrm{~g} \mathrm{dl}^{-1}$, platelets $\geqslant 100000 \mu \mathrm{l}^{-1}$ ), adequate liver function tests (ALT/AST $<3 \times \mathrm{ULN}$, total bilirubin of $1.5 \mathrm{mg} \mathrm{dl}^{-1}$ or less), and creatinine of $\leqslant 2.0 \mathrm{mg} \mathrm{dl}^{-1}$. Exclusion criteria included prior systemic chemotherapy for CRPC, prior exposure to temsirolimus, known HIV positivity, known brain metastases, and the use of any other experimental drug therapy within 28 days of study entry. Patients were allowed to receive intravenous or oral bisphosphonates for their bone metastases and were mandated to continue androgen suppression therapy while on study. Steroids were allowed concomitantly only if they were taken for another chronic medical condition. All subjects signed the written informed consent that was reviewed by the local institutional board as dictated by the declaration of Helsinki for human subject protection.

Study design. Patients received temsirolimus $25 \mathrm{mg}$ per week given as a $30-60 \mathrm{~min}$ intravenous infusion on days $1,8,15$, and 22 repeated every 28 days in this open label study. Four weeks of therapy constituted one cycle of treatment. Treatment continued until voluntary withdrawal, toxicity, objective disease progression, or the investigator's discretion. The trial was registered at www.clinicaltrials.gov (NCT00919035).

Study objectives and end points. The primary end point was calculating the sum of the complete response (CR), partial response $(\mathrm{PR})$, and stable disease (SD) on radiographic imaging. All responses were confirmed using the PSWG-2 criteria. Complete response was defined as the disappearance of all measurable lesions including bone lesions detected on bone scans, no evidence of new lesions, and no disease-related symptoms. Partial response was defined as more than $30 \%$ decreases in the sum of the longest diameter of measurable lesions compared with baseline. Stable disease was defined as no significant decrease in lesions to constitute PR or CR and no sufficient increase to meet criteria for progressive disease (PD). Progressive disease was defined as more than $20 \%$ increase in the sum of the longest diameter of measurable lesions compared with baseline, and/or evidence of new lesions on imaging studies, the appearance of two or more new bony lesions on a bone scan, or newly developed cord compression or pathologic fracture. Percentage of patients achieving SD was calculated and defined as these who are achieving a clinical benefit without actual radiographic response. Secondary end points were toxicity, time to disease progression, PSA response, overall survival (OS), and the impact of temsirolimus on quality of life (QoL). Prostatic-specific antigen responses were measured as per Scher et al (Scher et al, 2008).

Assessments. Baseline evaluation included a complete history and physical exam including vital signs and performance status, complete blood count, comprehensive metabolic panel, fasting lipid panel, serum testosterone measurement, 12-lead electrocardiogram, CT-scans of measurable disease areas, bone scan, and brain imaging where indicated clinically. Responses were assessed every 8 weeks using the Response Evaluation Criteria in Solid Tumors (RECIST) (Tsuchida and Therasse, 2001; Therasse et al, 2006). PSA was measured every 8 weeks. Quality of life measures were assessed prospectively using two previously validated scales; the Brief Pain Inventory (BPI) and the M.D. Anderson Symptom Inventory (MDASI) (Cleeland and Ryan, 1994; Cleeland et al, 2000).

Safety and dosing. Toxicity was documented every 4 weeks using the latest version of the Common Toxicity Criteria for Adverse Events (CTCAE) at the time of initiating the study. Temsirolimus dose was held for absolute neutrophil count $<1000 \mathrm{ul}^{-1}$, platelet count $<75000 \mathrm{ul}^{-1}$, or grade 3 adverse event. Once toxicities resolve to grade 2 or less, the drug was resumed at $5 \mathrm{mg}$ per week lower dose (i.e., $25 \mathrm{mg}$ weekly became $20 \mathrm{mg}$ weekly, and if the patient was on $20 \mathrm{mg}$ weekly dose became $15 \mathrm{mg}$ weekly). Patients who required a dose reduction to less than $15 \mathrm{mg}$ weekly were taken off study.

Quality of life. Quality of life and pain assessments were performed at baseline and every 8 weeks thereafter. A component score for the MDASI symptom severity scale was obtained using the average score for the first 13 items. The mean of the interference items (questions 14-19) was used to represent overall symptom distress (Fleming et al, 2012). Pain interference was scored as the mean of the seven interference items of the BPI (Gore, 2007).

Statistical analysis. The study aimed at enrolling 25 patients. Based on Simon two-stage phase II design, seven patients would be enrolled initially. If $<1$ response or SD was observed, the study would be stopped and the drug would be deemed ineffective. If $>2$ responses or SD were seen, the study would continue to accrue additional 18 patients for the total of 25 patients. If six or fewer 
responses or $\mathrm{SD}$ were observed out of these 25 patients, the drug would be deemed ineffective. If seven or more responses or SD, the drug would be considered effective and worthy of further investigation. This sample would provide an $80 \%$ power to detect a clinical benefit defined as the sum of CR, PR, and SD between 15 and 40\% (Type I error is controlled at 0.05 level). In 2012, after 21 patients were enrolled, the funding source (Pfizer) withdrew support to this study; accordingly, the trial was closed and halted accrual.

\section{RESULTS}

Patients and disease characteristics. Between 2009 and 2012, 21 patients were enrolled and 15 were evaluable for response. The remaining six patients completed less than two cycles of temsirolimus and hence were included only in the toxicity analysis. Baseline demographics are shown in Table 1. Median PSA was $237.5 \mathrm{ng} \mathrm{ml}^{-1}$ (range 8.2-2360.6). Sites of metastatic disease included bone only $(n=6)$, bone and visceral disease $(n=11)$, bone and lymph node involvement $(n=3)$, and lymph node involvement only $(n=1)$. Median time on androgen deprivation therapy before study enrolment was 60 months (range 17-240 months).

Efficacy results. Fifteen patients were evaluable for radiographic response. Although no patient had a CR, two patients had a PR, eight demonstrated SD, and the remaining five patients had PD. Partial response patients were confirmed as per the PCWG2 criteria. The overall response rate (OR) was $13 \%(2 / 15)$ and the overall clinical benefit $(\mathrm{OR}+\mathrm{SD})$ was $67 \%(10 / 15)$. Median time to radiographic disease progression was 2 months (range 2-10 months).

Biochemical response assessment was available for 14/15 patients (one patient had no PSA at study exit per his choice).

\begin{tabular}{|c|c|}
\hline \multicolumn{2}{|l|}{ Table 1. Baseline characteristics $(n=21)$} \\
\hline Median age, years (range) & $74(57-89)$ \\
\hline Time since diagnosis, months (range) & $120(17-331)$ \\
\hline PSA (ng ml-1), median (range) & $238(8.0-2.361)$ \\
\hline Time on $\mathrm{ADT}^{\mathrm{a}}$, months (range) & $60(17-240)$ \\
\hline Alkaline phosphatase $\left(\mathrm{Ul}^{-1}\right)$, median (range) & $104(57-869)$ \\
\hline Analgesic use, n (\%) & $7(33)$ \\
\hline \multicolumn{2}{|l|}{ Site of metastases, n (\%) } \\
\hline $\begin{array}{l}\text { Bone } \\
\text { Bone and visceral } \\
\text { Bone and lymph node } \\
\text { Lymph node }\end{array}$ & $\begin{array}{c}6(29) \\
11(52) \\
3(14) \\
1(5)\end{array}$ \\
\hline \multicolumn{2}{|l|}{ ECOG performance status, $n(\%)$} \\
\hline $\begin{array}{l}0 \\
1 \\
2\end{array}$ & $\begin{array}{c}10(48) \\
10(48) \\
1(5)\end{array}$ \\
\hline \multicolumn{2}{|l|}{ Gleason score, n (\%) } \\
\hline $\begin{array}{l}\geqslant 7 \\
<7 \\
\text { Unknown }\end{array}$ & $\begin{array}{l}17(81) \\
3(14) \\
1(5)\end{array}$ \\
\hline 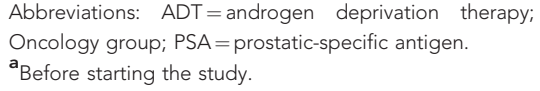 & $E C O G=$ eastern Cooperative \\
\hline
\end{tabular}

Any PSA decline was observed in four patients $(28.5 \% ; 4 / 14)$ with one patient $(7 \%)$ having $>50 \%$ PSA decline (Figure 1). Prostaticspecific antigen declines were confirmed as per the PCWG2 criteria. No changes to PSA doubling times were observed while patients were on study. Median time to progression by PSA was 2 months (range 1-10 months). With a median follow-up of 32 months, median OS was 13 months (range: 2-37) and three patients remain alive at the data cutoff (5/2013) for an OS of $14 \%$ at 4 years on an intent-to-treat analysis.

Subsequent therapies were captured for enrolled patients. Eight patients (38\%) received systemic chemotherapy, four (19\%) were treated with sipuleucel-T, five patients (24\%) declined additional therapy, and one patient (5\%) received palliative radiotherapy.

Toxicity and adverse events. A median of two cycles of temsirolimus was (Tables 2 and 3) administered (range: 1-11 cycles). Two patients (10\%) completed 10 cycles of treatment, before demonstrating disease progression. In total, eight patients (38\%) required dose reductions, five of which were related to thrombocytopenia. The three other dose reductions were related to fatigue and hypertriglyceridemia. Three of these eight patients required subsequent dose reductions due to thrombocytopenia.

All 21 patients were evaluable for toxicity. The most common Grade 3 or 4 toxicities were fatigue in 19\%, pain, and pneumonias in $14 \%$ each. Grade 3 or 4 laboratory abnormalities were also noted. Thrombocytopenia (33\%); hyperglycaemia (24\%); and lymphopenia (24\%); were the most common. Serious adverse events (SAEs) occurred in 11 patients (52\%). Serious adverse events included: urinary tract infection, dehydration, weakness, transient ischaemic attack, pneumonia, pain, renal failure, anaemia, urinary retention, shortness of breath, deep vein thrombosis, acute arterial ischaemia, fever, and intracranial bleed. Of the SAEs reported, anaemia was considered related to study drug, whereas the remaining SAEs were not or possible related. There were three deaths during the study period but none of these were linked to the study drug. One patient died from surgical complications of a gangrenous foot (related to long standing vascular disease and diabetes), another from intracranial bleed, and a third from disease progression.

Quality of life data analysis. Completed MDASI and BPI questionnaires were available for 14 patients after the initial baseline assessment. Comparison of the baseline scores to the scores at the final study visit showed no significant difference and no adverse impact of the drug on QoL. Three separate domains were evaluated, including symptom severity, symptom interference with daily life, and pain scores. Symptom severity was calculated by averaging responses to items $1-13$ on the MDASI. Patients rated

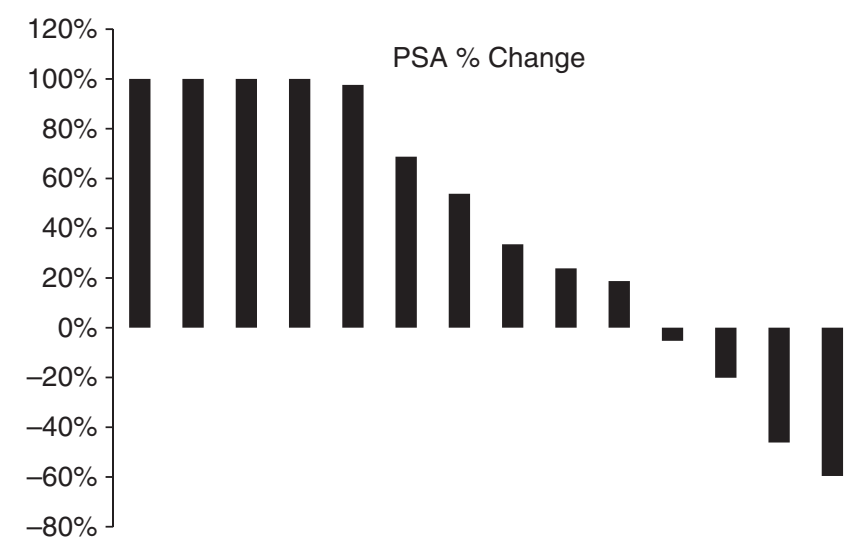

Figure 1. Waterfall Plot for PSA changes in the 14 patients evaluable biochemically. 


\begin{tabular}{|c|c|c|c|c|}
\hline & \multicolumn{2}{|c|}{ Grade 1 or 2} & \multicolumn{2}{|c|}{ Grade 3 or 4} \\
\hline Adverse event & No & Frequency (\%) & No & Frequency (\%) \\
\hline \multicolumn{5}{|l|}{ Nonhematologic } \\
\hline Pain & 12 & 57 & 3 & 14 \\
\hline Anorexia & 11 & 52 & 1 & 5 \\
\hline Fatigue & 11 & 52 & 4 & 19 \\
\hline Constipation & 9 & 43 & 0 & 0 \\
\hline Rash & 8 & 38 & 0 & 0 \\
\hline Depression & 6 & 29 & 0 & 0 \\
\hline Oedema & 6 & 29 & 0 & 0 \\
\hline Mucositis & 6 & 29 & 0 & 0 \\
\hline Weight loss & 6 & 29 & 0 & 0 \\
\hline Neuropathy & 5 & 24 & 1 & 5 \\
\hline Nausea & 3 & 14 & 1 & 5 \\
\hline Dehydration & 2 & 10 & 1 & 5 \\
\hline Pneumonia & 1 & 5 & 3 & 14 \\
\hline Urinary tract infection & 0 & 0 & 1 & 5 \\
\hline TIA & 0 & 0 & 1 & 5 \\
\hline DVT & 0 & 0 & 1 & 5 \\
\hline Stroke & 0 & 0 & 1 & 5 \\
\hline \multicolumn{5}{|c|}{ Laboratory abnormalities } \\
\hline Elevated triglycerides & 11 & 52 & 1 & 5 \\
\hline Hyperglycaemia & 11 & 52 & 5 & 24 \\
\hline Hypoalbuminemia & 10 & 48 & 0 & 0 \\
\hline Hypocalcemia & 8 & 38 & 1 & 5 \\
\hline High cholesterol & 8 & 38 & 1 & 5 \\
\hline AST elevation & 6 & 29 & 1 & 5 \\
\hline Elevated alk phos & 5 & 24 & 1 & 5 \\
\hline Hypokalemia & 5 & 24 & 0 & 0 \\
\hline Elevated creatinine & 5 & 24 & 1 & 5 \\
\hline Hyponatremia & 4 & 19 & 1 & 5 \\
\hline ALT elevation & 2 & 10 & 0 & 0 \\
\hline Hypophosphatemia & 2 & 10 & 3 & 14 \\
\hline \multicolumn{5}{|l|}{ Haematologic } \\
\hline Leucopenia & 16 & 76 & 0 & 0 \\
\hline Anaemia & 13 & 62 & 3 & 14 \\
\hline Thrombocytopenia & 9 & 43 & 7 & 33 \\
\hline Lymphopenia & 8 & 38 & 5 & 24 \\
\hline
\end{tabular}

their symptoms on a scale of $0-10$ with an average symptom severity score of 1.58 at baseline and 1.96 at final visit. Symptom interference score was evaluated using items 14-19 of the MDASI. Patients reported an average symptom interference score of 2.01 at baseline and 1.79 at the final visit. Similar results were obtained using the BPI scale. Within the limitation of these small numbers, none of these differences appeared statistically significant.

\section{DISCUSSION}

In this phase II study, we show that temsirolimus has minimal activity in chemotherapy-naïve CRPC. Biochemical responses were modest, but two patients had objective response radiographically. To our knowledge, this is the first report of activity of temsirolimus in this particular patient population.

In addition to its known indication in renal cell cancer, previous studies have demonstrated minimal single-agent activity of

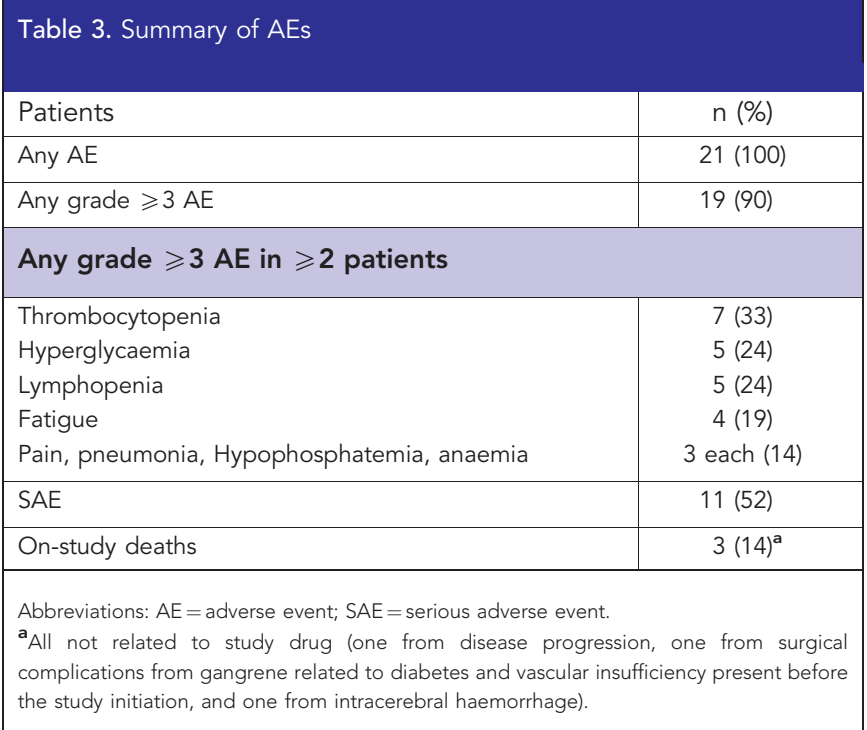

temsirolimus in cervical, breast, and epithelial ovarian cancer/ primary peritoneal cancer (Behbakht et al, 2011; Fleming et al, 2012; Tinker et al, 2013). In these studies, however, responses were modest with some patients achieving disease stability radiographically. Toxicities were minimal and consistent with known adverse events reported in pivotal renal cancer studies. (Bhojani et al, 2008) In combination with bevacizumab, temsirolimus showed higher response rates in patients with advanced melanoma and relapsed endometrial carcinoma but these were marginal and short-lived (Alvarez et al, 2013; Slingluff et al, 2013). Although these studies showed marginal benefit, these results coupled with the accumulated evidence of the PTEN deregulation in advanced prostate cancer suggested that further investigation of temsirolimus in this setting is justified (Pourmand et al, 2007; Schmitz et al, 2007; Shen and Abate-Shen, 2007; de Muga et al, 2010).

In our study, disease stabilisation occurred in the majority of patients but two patients demonstrated PR radiographically. Stability of metastatic disease clinically and radiographically could provide metastatic incurable patients with an appreciable and meaningful benefit. Although it remains uncertain whether clinical benefit defined as SD correlates with OS in prostate cancer, this concept has been suggested in other solid malignancies (Takahashi et al, 2000; He et al, 2010; Kim et al, 2010). Early studies in prostate cancer suggested that PR and SD patients treated with cytotoxic therapy might derive similar therapeutic benefit. (Slack et al, 1980, 1984) However, modern studies have yet to demonstrate similar findings. We propose that further understanding of the impact of $\mathrm{SD}$ on survival and other outcome measures warrant rigorous investigation.

Observed toxicities in our study were predictable. Myleosuppression was notable, as five patients required a dose reduction owing to thrombocytopenia and three of these required an additional dose reduction for the same reason. Thrombocytopenia has been reported in nearly all studies of temsirolimus and in most cases was mild and manageable. Additional laboratory toxicities of hyperglycaemia (24\% grade $3 / 4$ ) and hyperlipidemia (5\% grade $3 / 4$ and $38 \%$ grade $1 / 2$ ) were also observed. Interestingly, it has been reported that patients with renal cell carcinoma who have elevation in cholesterol while receiving temsirolimus have superior survival compared with others with no changes in cholesterol values. (Lee et al, 2012) Additional grade $3 / 4$ adverse events were observed; fatigue (19\%), pneumonia (14\%), and pain (14\%). Further, 52\% of patients encountered SAEs. However, these witnessed toxicities in our study did not affect QoL of treated patients. Incorporating QoL 
measures with traditional biochemical and radiographic responses remains challenging and is not uniformly reported in prospective studies. Two previously validated and widely used scales were implemented in this study. The MDASI and BPI assessed symptom severity, interference in daily life, and the average pain score at each study visit. Neither of these scales was specific for patients with advanced prostate cancer. Nevertheless, the questionnaires in both scales addressed commonly encountered problems in patients with advanced malignancies. Our data show no significant adverse impact on QoL. Although there continues to be a debate as to what is the best measure to assess QoL, (Colloca and Colloca, 2011) establishing a consistent way of measuring QoL across trials will become increasingly important as more agents become available. Importantly, most QoL studies have generally focused on evaluating toxicities of early disease treatment (i.e., surgery, radiotherapy, $\mathrm{ADT}$, and brachytherapy) (Hoskin et al, 2013; Komiya et al, 2013; Mc Caughan et al, 2013; van Tol-Geerdink et al, 2013) with fewer studies assessing the impact of cytotoxic chemotherapy (Caffo et al, 2011). Critically, as newer targeted agents become increasingly utilised in CRPC and as these agents have different toxicity profile than traditional chemotherapy, evaluating their impact on QoL will be essential moving forward.

Few studies explored the activity of mTOR inhibitors in CRPC. In a single-arm phase II study, 37 chemotherapy-naïve patients with CRPC were treated with everolimus continuously at $10 \mathrm{mg}$ daily (Templeton et al, 2013). The primary end point of PFS at 12 weeks was met by 13 patients (35\%) with 2 patients having $>50 \%$ PSA decline. Armstrong et al (2013) conducted a phase II study with weekly temsirolimus in patients with chemotherapy-refractory CRPC who had more than five circulating tumour cells (CTCs) at baseline. Although the trial aimed at enrolling 20 patients, it was halted prematurely after 11 patients were treated due to lack of activity. However, this study's primary end point was the change in CTCs at 8 weeks and $73 \%$ of men had persistently unfavourable CTCs $(\geqslant 5)$ over time and only 1 patient had a $\geqslant 30 \%$ PSA decline. Median progression-free survival was 1.9 months and median OS was 8.8 months. These studies along with our report suggest that $\mathrm{mTOR}$ inhibitors have minimal activity in CRPC and a benefit might be observed earlier in the course of this disease before chemotherapy refractoriness. Further, studying these agents only in patients who manifest a PTEN mutation might prove beneficial.

The median OS of 13 months was less than ideal for a chemotherapy-naïve patient population. Whether this suggests that temsirolimus had an adverse impact on outcome cannot be determined. Other possibilities include the fact that only $38 \%$ of enrolled patients received chemotherapy after progression, whereas $24 \%$ of patients refused any additional therapy. This precluded patients from receiving some of the newer available agents that have become available. Since the inception of this trial, newer therapeutic interventions have become widely available for CRPC. In the asymptomatic setting, Kantoff et al (Kantoff et al, 2010) reported on the activity of sipuleucel-T, an autologous cellular immunotherapy, demonstrating that this agent improves OS when compared with control. The abundance of data showing continued AR activation even in the CRPC setting has led to developing agents targeting the AR pathway. Abiraterone, an androgen biosynthesis inhibitor, improved OS in CRPC patients who have failed docetaxel (de Bono et al, 2011) and also approved in the chemotherapy-naïve setting (Ryan et al, 2013). Enzalutamide, an AR inhibitor, was also shown to improve OS in CRPC patients who failed prior chemotherapy (Scher et al, 2012). The availability of these newer therapies in the same space where our study was conducted might have led the sponsor to halt the study prematurely, as difficulty in accruing patients was anticipated with more available commercial treatment choices. However, the cross talk between the AR and mTOR pathways that has been established in several in vitro studies might lead to suggest combining agents targeting both pathways for ultimate inhibition of CRPC progression (Lin et al, 2004; Carver et al, 2011; Wang et al, 2011).

As current and future newer therapies will become available for patients with CRPC, exploring whether MTOR inhibitors have any future roles in CRPC is challenging. The collective evidence suggests that mTOR inhibitors' activity is limited to a small subset of patients. We propose that future studies with these agents are limited to combination programs with other targeted agents, preferably these targeting the AR pathway.

\section{REFERENCES}

Alvarez EA, Brady WE, Walker JL, Rotmensch J, Zhou XC, Kendrick JE Yamada SD, Schilder JM, Cohn DE, Harrison CR, Moore KN, Aghajanian C (2013) Phase II trial of combination bevacizumab and temsirolimus in the treatment of recurrent or persistent endometrial carcinoma: a Gynecologic Oncology Group study. Gynecol Oncol 129(1): 22-27.

Armstrong A, Shen T, Halabi S, Kemeny G, Bitting R, Kartcheske P, Embree E, Morris K, Winters C, Jaffe T, Fleming M, George D (2013) A phase II trial of temsirolimus in men with castration-resistant metastatic prostate cancer. Clin Genitourin Cancer; e-pub ahead of print 3 July 2013; doi:10.1016/j.clgc.2013.05.007.

Behbakht K, Sill MW, Darcy KM, Rubin SC, Mannel RS, Waggoner S, Schilder RJ, Cai KQ, Godwin AK, Alpaugh RK (2011) Phase II trial of the mTOR inhibitor, temsirolimus and evaluation of circulating tumor cells and tumor biomarkers in persistent and recurrent epithelial ovarian and primary peritoneal malignancies: a Gynecologic Oncology Group study. Gynecol Oncol 123(1): 19-26.

Bhojani N, Jeldres C, Patard JJ, Perrotte P, Suardi N, Hutterer G, Patenaude F, Oudard S, Karakiewicz PI (2008) Toxicities associated with the administration of sorafenib, sunitinib, and temsirolimus and their management in patients with metastatic renal cell carcinoma. Eur Urol 53(5): 917-930.

Burgio SL, Fabbri F, Seymour IJ, Zoli W, Amadori D, De Giorgi U (2012) Perspectives on mTOR inhibitors for castration-refractory prostate cancer. Curr Cancer Drug Targets 12(8): 940-949.

Caffo O, Sava T, Comploj E, Fariello A, Zustovich F, Segati R, Sacco C, Veccia A, Galligioni E (2011) Impact of docetaxel-based chemotherapy on quality of life of patients with castration-resistant prostate cancer: results from a prospective phase II randomized trial. BJU Int 108(11): 1825-1832.

Carver BS, Chapinski C, Wongvipat J, Hieronymus H, Chen Y, Chandarlapaty S, Arora VK, Le C, Koutcher J, Scher H, Scardino PT, Rosen N, Sawyers CL (2011) Reciprocal feedback regulation of PI3K and androgen receptor signaling in PTEN-deficient prostate cancer. Cancer Cell 19(5): 575-586.

Chen CD, Welsbie DS, Tran C, Baek SH, Chen R, Vessella R, Rosenfeld MG, Sawyers CL (2004) Molecular determinants of resistance to antiandrogen therapy. Nature Med 10(1): 33-39.

Cleeland CS, Mendoza TR, Wang XS, Chou C, Harle MT, Morrissey M, Engstrom MC (2000) Assessing symptom distress in cancer patients: the M.D. Anderson Symptom Inventory. Cancer 89(7): 1634-1646.

Cleeland CS, Ryan KM (1994) Pain assessment: global use of the Brief Pain Inventory. Ann Acad Med Singapore 23(2): 129-138.

Colloca G, Colloca P (2011) Health-related quality of life assessment in prospective trials of systemic cytotoxic chemotherapy for metastatic castration-resistant prostate cancer: which instrument we need? Med Oncol 28(2): 519-527.

de Bono JS, Logothetis CJ, Molina A, Fizazi K, North S, Chu L, Chi KN, Jones RJ, Goodman Jr OB, Saad F, Staffurth JN, Mainwaring P, Harland S, Flaig TW, Hutson TE, Cheng T, Patterson H, Hainsworth JD, Ryan CJ, Sternberg CN, Ellard SL, Flechon A, Saleh M, Scholz M, Efstathiou E, Zivi A, Bianchini D, Loriot Y, Chieffo N, Kheoh T, Haqq CM, Scher HI. Investigators C-A- (2011) Abiraterone and increased survival in metastatic prostate cancer. N Engl J Med 364(21): 1995-2005.

de Bono JS, Oudard S, Ozguroglu M, Hansen S, Machiels JP, Kocak I, Gravis G, Bodrogi I, Mackenzie MJ, Shen L, Roessner M, Gupta S, Sartor AO (2010) Prednisone plus cabazitaxel or mitoxantrone for metastatic castration-resistant prostate cancer progressing after docetaxel treatment: a randomised open-label trial. Lancet 376(9747): 1147-1154. 
de Muga S, Hernandez S, Agell L, Salido M, Juanpere N, Lorenzo M, Lorente JA, Serrano S, Lloreta J (2010) Molecular alterations of EGFR and PTEN in prostate cancer: association with high-grade and advanced-stage carcinomas. Mod Pathol 23(5): 703-712.

Debes JD, Tindall DJ (2004) Mechanisms of androgen-refractory prostate cancer. N Engl J Med 351(15): 1488-1490.

Fleming GF, Ma CX, Huo D, Sattar H, Tretiakova M, Lin L, Hahn OM, Olopade FO, Nanda R, Hoffman PC, Naughton MJ, Pluard T, Conzen SD, Ellis MJ (2012) Phase II trial of temsirolimus in patients with metastatic breast cancer. Breast Cancer Res Treat 136(2): 355-363.

Gore ME (2007) Temsirolimus in the treatment of advanced renal cell carcinoma. Ann Oncol 18(Suppl 9): ix87-ix88.

He L, Teng Y, Jin B, Zhao M, Yu P, Hu X, Zhang J, Li S, Gao Y, Liu Y (2010) Initial partial response and stable disease according to RECIST indicate similar survival for chemotherapeutical patients with advanced non-small cell lung cancer. BMC Cancer 10: 681.

Hoskin PJ, Rojas AM, Ostler PJ, Hughes R, Lowe GJ, Bryant L (2013) Quality of life after radical radiotherapy for prostate cancer: longitudinal study from a randomised trial of external beam radiotherapy alone or in combination with high dose rate brachytherapy. Clin Oncol 25(5): 321-327.

Kantoff PW, Higano CS, Shore ND, Berger ER, Small EJ, Penson DF, Redfern CH, Ferrari AC, Dreicer R, Sims RB, Xu Y, Frohlich MW, Schellhammer PF (2010) Sipuleucel-T immunotherapy for castration-resistant prostate cancer. $N$ Engl J Med 363(5): 411-422.

Kim HR, Kang MS, Na II, Yang SH, Choi YH, Kang HJ, Kim CH, Lee JC (2010) The similar survival benefits of stable disease and partial response to pemetrexed in previously treated non-small cell carcinoma patients. J Cancer Res Clin Oncol 136(4): 547-552.

Komiya A, Fujiuchi Y, Ito T, Morii A, Yasuda K, Watanabe A, Nozaki T, Iida H, Nomura K, Fuse H (2013) Early quality of life outcomes in patients with prostate cancer managed by high-dose-rate brachytherapy as monotherapy. Int J Urol 20(2): 185-192.

Lee CK, Marschner IC, Simes RJ, Voysey M, Egleston B, Hudes G, de Souza P (2012) Increase in cholesterol predicts survival advantage in renal cell carcinoma patients treated with temsirolimus. Clin Cancer Res 18(11): 3188-3196.

Li J, Yen C, Liaw D, Podsypanina K, Bose S, Wang SI, Puc J, Miliaresis C, Rodgers L, McCombie R, Bigner SH, Giovanella BC, Ittmann M, Tycko B, Hibshoosh H, Wigler MH, Parsons R (1997) PTEN, a putative protein tyrosine phosphatase gene mutated in human brain, breast, and prostate cancer. Science 275(5308): 1943-1947.

Lin HK, Hu YC, Lee DK, Chang C (2004) Regulation of androgen receptor signaling by PTEN (phosphatase and tensin homolog deleted on chromosome 10) tumor suppressor through distinct mechanisms in prostate cancer cells. Mol Endocrinol 18(10): 2409-2423.

Mc Caughan E, Mc Sorley O, Prue G, Parahoo K, Bunting B, Sullivan JO, McKenna H (2013) Quality of life in men receiving radiotherapy and neoadjuvant androgen deprivation for prostate cancer: results from a prospective longitudinal study. J Adv Nurs 69(1): 53-65.

Nabhan C, Parsons B, Touloukian EZ, Stadler WM (2011) Novel approaches and future directions in castration-resistant prostate cancer. Ann Oncol 22(9): 1948-1957.

Neppl-Huber C, Zappa M, Coebergh JW, Rapiti E, Rachtan J, Holleczek B, Rosso S, Aareleid T, Brenner H, Gondos A, Group ESW (2012) Changes in incidence, survival and mortality of prostate cancer in Europe and the United States in the PSA era: additional diagnoses and avoided deaths. Ann Oncol 23(5): 1325-1334.

Pourmand G, Ziaee AA, Abedi AR, Mehrsai A, Alavi HA, Ahmadi A, Saadati HR (2007) Role of PTEN gene in progression of prostate cancer. Urol J 4(2): 95-100.

Ryan CJ, Smith MR, de Bono JS, Molina A, Logothetis CJ, de Souza P, Fizazi K, Mainwaring P, Piulats JM, Ng S, Carles J, Mulders PF, Basch E, Small EJ, Saad F, Schrijvers D, Van Poppel H, Mukherjee SD, Suttmann H Gerritsen WR, Flaig TW, George DJ, Yu EY, Efstathiou E, Pantuck A, Winquist E, Higano CS, Taplin ME, Park Y, Kheoh T, Griffin T, Scher HI, Rathkopf DE (2013) Abiraterone in metastatic prostate cancer without previous chemotherapy. N Engl J Med 368(2): 138-148.
Scher HI, Fizazi K, Saad F, Taplin ME, Sternberg CN, Miller K, de Wit R, Mulders P, Chi KN, Shore ND, Armstrong AJ, Flaig TW, Flechon A, Mainwaring P, Fleming M, Hainsworth JD, Hirmand M, Selby B, Seely L, de Bono JS (2012) Increased survival with enzalutamide in prostate cancer after chemotherapy. N Engl J Med 367(13): 1187-1197.

Scher HI, Halabi S, Tannock I, Morris M, Sternberg CN, Carducci MA, Eisenberger MA, Higano C, Bubley GJ, Dreicer R, Petrylak D, Kantoff P, Basch E, Kelly WK, Figg WD, Small EJ, Beer TM, Wilding G, Martin A, Hussain M (2008) Design and end points of clinical trials for patients with progressive prostate cancer and castrate levels of testosterone: recommendations of the Prostate Cancer Clinical Trials Working Group. J Clin Oncol 26(7): 1148-1159.

Schmitz M, Grignard G, Margue C, Dippel W, Capesius C, Mossong J, Nathan M, Giacchi S, Scheiden R, Kieffer N (2007) Complete loss of PTEN expression as a possible early prognostic marker for prostate cancer metastasis. Int J Cancer 120(6): 1284-1292.

Shen MM, Abate-Shen C (2007) Pten inactivation and the emergence of androgen-independent prostate cancer. Cancer Res 67(14): 6535-6538.

Shibata A, Whittemore AS (2001) Re: Prostate cancer incidence and mortality in the United States and the United Kingdom. J Natl Cancer Inst 93(14): $1109-1110$.

Siegel R, Naishadham D, Jemal A (2013) Cancer statistics, 2013. CA Cancer J Clin 63(1): 11-30.

Slack NH, Brady MF, Murphy GP (1984) Stable versus partial response in advanced prostate cancer. Prostate 5(4): 401-415.

Slack NH, Mittelman A, Brady MF, Murphy GP (1980) The importance of the stable category for chemotherapy treated patients with advanced and relapsing prostate cancer. Cancer 46(11): 2393-2402.

Slingluff Jr CL, Petroni GR, Molhoek KR, Brautigan DL, Chianese-Bullock KA, Shada AL, Smolkin ME, Olson WC, Gaucher A, Chase CM, Grosh WW, Weiss GR, Wagenseller AG, Olszanski AJ, Martin L, Shea SM, Erdag G, Ram PT, Gershenwald JE, Weber MJ (2013) Clinical activity and safety of combination therapy with temsirolimus and bevacizumab for advanced melanoma: A Phase II trial (CTEP 7190/ Mel47). Clin Cancer Res 19(13): 3611-3620.

Takahashi Y, Mai M, Taguchi T, Urushizaki I, Nishioka K (2000) Prolonged stable disease effects survival in patients with solid gastric tumor: analysis of phase II studies of doxifluridine. Int J Oncol 17(2): 285-289.

Templeton AJ, Dutoit V, Cathomas R, Rothermundt C, Bartschi D, Droge C, Gautschi O, Borner M, Fechter E, Stenner F, Winterhalder R, Muller B, Schiess R, Wild PJ, Ruschoff JH, Thalmann G, Dietrich PY, Aebersold R, Klingbiel D, Gillessen S. Swiss Group for Clinical Cancer R (2013) Phase 2 trial of single-agent everolimus in chemotherapy-naive patients with castration-resistant prostate cancer (SAKK 08/08). Eur Urol 64(1): $150-158$.

Therasse P, Eisenhauer EA, Verweij J (2006) RECIST revisited: a review of validation studies on tumour assessment. Eur J Cancer 42(8): 1031-1039.

Tinker AV, Ellard S, Welch S, Moens F, Allo G, Tsao MS, Squire J, Tu D, Eisenhauer EA, Mackay H (2013) Phase II study of temsirolimus (CCI779) in women with recurrent, unresectable, locally advanced or metastatic carcinoma of the cervix. A trial of the NCIC Clinical Trials Group (NCIC CTG IND 199). Gynecol Oncol 130(2): 269-274.

Tsuchida Y, Therasse P (2001) Response evaluation criteria in solid tumors (RECIST): new guidelines. Med Pediatr Oncol 37(1): 1-3.

van Tol-Geerdink JJ, Leer JW, van Oort IM, van Lin EJ, Weijerman PC, Vergunst H, Witjes JA, Stalmeier PF (2013) Quality of life after prostate cancer treatments in patients comparable at baseline. Br J Cancer 108(9): 1784-1789.

Wang Y, Romigh T, He X, Tan MH, Orloff MS, Silverman RH, Heston WD, Eng C (2011) Differential regulation of PTEN expression by androgen receptor in prostate and breast cancers. Oncogene 30(42): 4327-4338.

This work is published under the standard license to publish agreement. After 12 months the work will become freely available and the license terms will switch to a Creative Commons AttributionNonCommercial-Share Alike 3.0 Unported License. 